\title{
Rest energy expenditure is decreased during the acute as compared to the recovery phase of sepsis in newborns
}

\author{
Rubens Feferbaum ${ }^{1 *}$, Cláudio Leone ${ }^{2}$, Arnaldo AF Siqueira², Vitor E Valenti ${ }^{3,4}$, Paulo R Gallo², Alberto OA Reis ${ }^{2}$, \\ Ary C Lopes ${ }^{1}$, Viviane G Nascimento, Adriana G de Oliveira², Tatiana Dias de Carvalho ${ }^{3}$, Rubens Wajnsztejn ${ }^{2,4}$, \\ Claudia de Castro Selestrin², Luiz Carlos de Abreu ${ }^{2,4}$
}

\begin{abstract}
Background: Little is known with respect to the metabolic response and the requirements of infected newborns. Moreover, the nutritional needs and particularly the energy metabolism of newborns with sepsis are controversial matter. In this investigation we aimed to evaluate the rest energy expenditure (REE) of newborns with bacterial sepsis during the acute and the recovery phases.

Methods: We studied nineteen neonates $(27.3 \pm 17.2$ days old $)$ with bacterial sepsis during the acute phase and recovery of their illness. REE was determined by indirect calorimetry and $\mathrm{VO}_{2}$ and $\mathrm{VCO}_{2}$ measured by gas chromatography.

Results: REE significantly increased from $49.4 \pm 13.1 \mathrm{kcal} / \mathrm{kg} /$ day during the acute to $68.3 \pm 10.9 \mathrm{kcal} / \mathrm{kg} /$ day during recovery phase of sepsis $(P<0.01)$. Similarly, $V_{2}(7.4 \pm 1.9 \mathrm{vs} 10 \pm 1.5 \mathrm{ml} / \mathrm{kg} / \mathrm{min})$ and $\mathrm{VCO}_{2}(5.1 \pm 1.7 \mathrm{vs} 7.4 \pm 1.5$ $\mathrm{ml} / \mathrm{kg} / \mathrm{min})$ were also increased during the course of the disease $(P<0.01)$.

Conclusion: REE was increased during recovery compared to the sepsis phase. REE of septic newborns should be calculated on individualized basis, bearing in mind their metabolic capabilities.
\end{abstract}

\section{Introduction}

As compared with birth the body weight doubles at five months of age and is three-fold greater at the end of the first year of life. Their length increases approximately $25-30 \mathrm{~cm}$ in the first year of life, which represents 75 to $85 \%$ of the length at birth. As a result of such a rapid growth the requirements of nutrients and energy are higher during the neonatal period (especially preterm) as compared to later in life [1]. The most frequent infections during the neonatal period not only contribute to enhance morbidity and mortality rates [2], but may also impact on the energy and nutrient requirements.

In the presence of severe infection, the metabolic response is characteristically elevated, and in adults energy metabolism is higher following septicemia. Significant changes in protein metabolism and severe

\footnotetext{
* Correspondence: rfeferbaum@uol.com.br
'Departamento de Pediatria, Universidade de São Paulo (USP), São Paulo, SP,

* Correspondence: rfeferbaum@uol.com.br
'Departamento de Pediatria, Universidade de São Paulo (USP), São Paulo, SP, Brasil
}

(c) 2010 Feferbaum et al; licensee BioMed Central Ltd. This is an Open Access article distributed under the terms of the Creative

proteolysis occurs in muscle and visceral protein. As a consequence of these changes protein re-synthesis of immune factors, such as antibodies and acute phase reactants which the C-reactive protein (CRP) are generated $[3,4]$.

Resting energy expenditure (REE) is the amount of energy expended while at rest in a neutrally temperate environment in the post-absorptive state. The release of energy in this state is sufficient only for vital organs. REE decreases with age and is directly proportional to lean body mass [5-8].

Albeit previous studies assessed the metabolism of adults with sepsis, little is known regarding the metabolic response in septic infants. In addition, conflicting data are available about the nutritional requirements and the energy metabolism of infants $[9,10]$. Therefore, we aimed to evaluate REE in newborns with bacterial sepsis during the acute and the recovery phases of illness. We hypothesized that the newborn's metabolic 
demands are increased during recovery, when compared to the acute phase.

\section{Materials and methods Study Population}

This study protocol was approved by the University of Sao Paulo Research Ethics Board and subjects were only enrolled following parental consent.

We studied 19 children admitted in the University of Sao Paulo Neonatal Intensive Care Unit with the diagnosis of a bacterial sepsis. The subjects' were $20 \pm 17$ days old, birth weight of $2966 \pm 502$ grams and a male: female ratio of 10:9. Except for one (gestational age 35 weeks), all infants were full term.

\section{Inclusion Criteria}

The following inclusion was utilized: 1) age up to 90 days old; 2) birth weight higher than 1500 g; 3) clinical evidence of bacterial sepsis defined according to positive blood culture and/or modified clinical laboratory criteria of Bone [11]. We considered the measurement of Creactive protein (CRP) higher than $5 \mathrm{mg} /$ liter as suggestive of infection [12]. Other laboratory tests such as cerebrospinal fluid changes suggesting bacterial meningitis [13], chest X-rays with the image of bronchopneumonia were also considered auxiliary criteria for the diagnosis of bacterial sepsis.

\section{Exclusion Criteria}

Infants were excluded if presenting with liver or respiratory failure. The latter was defined or mechanical ventilation.

\section{Variables analysis}

The infant's medical management was determined by their attending physicians. The infants were evaluated time-in two periods: sepsis and recovery phases. The sepsis phase was characterized by a positive blood culture. The recovery phase was characterized by the normalization of blood count, CRP and a negative blood culture. Laboratory exams were performed according to the following techniques:

- Blood culture: collected in media for aerobic and anaerobic bacteria and plated on agar-blood;

- Blood cell count: automated method for the laser hematology counter CELL-DYN $3000^{\circ}$ that performs global and differential counts of platelets and formed elements with the confirmation of results for optical microscopy;

- CRP: measured by nephelometric technique using reagents "High sensitive CRP" and "Reagent additional Oumu-15" brand in Behring ${ }^{\oplus}$ device Behring ${ }^{\ominus}$ Nephelometer 100;
- Cerebrospinal fluid: according to the technique proposed by Spina-França, 1971.

Weight was measured daily throughout the hospitalization in an electronic scale accurate to 5 grams, with a capacity of $10 \mathrm{~kg}$, calibrated before each measurement. We calculated $\mathrm{Z}$ scores based on weight and chronological age. In order to calculate it we used the ANTHRO 1.01 program of the Nutrition Division of the Center for Disease Control (CDC-USA) and Nutrition Unit/World Health Organization, December, 1990.

Newborns received only parenteral nutrition, which was based on glucose as an energy source, especially in preterm infants, a fact also noted previously [14]. Test measurements were evaluated at least 12 hours after feeding.

The gestational age was calculated by the last menstrual period reported by the mother (Naegele's rule) and when possible we used the somatic Capurro method [15]. The classification of newborns with respect to birth weight and gestational age was based on the Brazilian Ramos curve [16].

Determination of indirect calorimetry was performed in two stages of the child evolution, always by the same investigator:

- On the acute phase of bacterial sepsis after hemodynamic stabilization which corresponds to the flow restoration level;

- On recovery phase of bacterial sepsis, when the newborn was considered clinically and biochemically free of infection by the attending physician, with the registry of the weight gain and at least 10 days after the first testing.

Assessment of indirect calorimetry is part of the routine tests performed in our center for newborns with metabolic and/or severe nutritional disorders requiring nutritional support. Details of our method to measure REE in newborns have been previously published by Cardoso et al [17]. They used the same technique of indirect calorimetry measurement in our study and demonstrated that the REE in malnourished infants was approximately $58.3+/-10.9 \mathrm{kcal} / \mathrm{kg}$ on hospitalization. Validation studies have shown the technique to give results equivalent to direct measurements $[16,18]$. The calorimeter used was developed by Hamamoto [19] and built from the incubator model C-86 of Fanem. Routine calibration was performed prior to each study using a $0.5 \mathrm{~L}$ syringe and primary standard calibration gases. Physical activity was assessed by the scale of Scopes and Ahmed [20], considering the scores 0 (sleep, eyes closed) and 1 (eyes open, physically still). 
The volume of air in the system was measured geometrically (140 liters), and the air flow around the fan was 75 liters per minute. On the anterior portion of the calorimeter there was a system of three-way taps to collect gas which is made with glass syringe fitted with locks and sealed with silicone. The test measurement involved placing the newborn in the incubator after feeding, keeping the ventilation ports opened, while temperature and humidity of the system and the newborn's home stabilize.

The gas collected $(20 \mathrm{~mL})$ were sent to the laboratory and analyzed by GC-35 chromatograph calibrated, the reading of the concentrations of oxygen and carbon dioxide were made in integrating CG processor 300 coupled to the gas chromatograph. One gas sample was needed to get a stable result. $\mathrm{VO}_{2}$ and $\mathrm{VCO}_{2}$ were corrected to standard conditions of pressure and temperature and we calculated REE using the modified Weir equation [21]:

$\operatorname{REE}(\mathrm{Kcal} / \mathrm{Kg} / 24$ hours $)=\left[\left(\mathrm{VO}_{2} \times 0.0039\right)+\left(\mathrm{VCO}_{2} \times 0.0011\right)\right] \times 1440$ minutes

$\mathrm{VO}_{2}=$ Oxygen uptake $(\mathrm{ml} / \mathrm{Kg} / \mathrm{min})$

$\mathrm{VCO}_{2}=$ Carbon dioxide production $(\mathrm{ml} / \mathrm{Kg} / \mathrm{min})$

$\mathrm{REE}=$ Resting Energy Expenditure $(\mathrm{Kcal} / \mathrm{Kg} /$ day $)$

\section{Statistical Analysis}

Data distribution was evaluated by D'Agostino Pearson normality test. Considering that all variables presented parametric distribution we used paired Student t-test to compare the acute and recovery phase values. The significance level were adopted for $1 \%(\mathrm{p}<0.01)$. The statistical analysis was conducted with Sigma Stat software.

\section{Results}

Four infants died during the study period due to worsening of their clinical condition. Table 1 lists the complete blood count, CRP and cultures results for the acute phase, while Table 2 shows similar data relative to the recovery phase.

Table 3 presents the clinical profile of all subjects.

We noted no changes in newborns oxygen saturation and axillary temperature. The respiratory quotient (RQ) data showed an average of 0.7 during sepsis, which is indicative of the predominant combustion of fat and ketone bodies, resulting in lower $\mathrm{CO}_{2}$ production.

During the acute phase of sepsis the REE was $49.4 \pm$ $13.1 \mathrm{kcal} / \mathrm{kg} /$ day and on recovery it significantly increased to $68.3 \pm 10.9 \mathrm{kcal} / \mathrm{kg} /$ day $(\mathrm{p}<0.01)$ (Figure 1$)$. Moreover, $\mathrm{VO}_{2}(7.4 \pm 1.9$ vs $10 \pm 1.5 \mathrm{ml} / \mathrm{kg} / \mathrm{min}$ ) (Figure 2) and $\mathrm{VCO}_{2}(5.1 \pm 1.7$ vs $7.4 \pm 1.5 \mathrm{ml} / \mathrm{kg} / \mathrm{min}$ ) (Figure 3) also increased during the recovery phase $(\mathrm{p}<0.01)$. Those findings support the hypothesis that the whole body metabolic rate is enhanced after sepsis recovery.

Table 4 shows data relative to age and weight changes during sepsis and recovery phase.

\section{Discussion}

We endeavored to evaluate the REE in newborn with bacterial sepsis at acute and recovery phases. We reported

Table 1 Complete blood count, CRP and cultures on acute phase of sepsis

\begin{tabular}{|c|c|c|c|c|c|c|c|}
\hline Subject & $\mathrm{Hb}(\mathrm{g} / \mathrm{dl})$ & Hct (\%) & $\mathrm{NI}$ & Leukocyte $/ \mathrm{mm}^{3}$ & Platelet $/ \mathrm{mm}^{3}$ & CRP (mg/l) & Identified bacteria \\
\hline 1 & 8.8 & 24 & 0.23 & 23500 & 32000 & - & HMC: Staphylococcus coagulase \\
\hline 2 & 10.6 & 30 & 0.02 & 12000 & 31400 & 9.82 & HMC: Klebsiella pneumoniae \\
\hline 3 & 14.4 & 41 & 0.20 & 8000 & 480000 & - & HMC: Escherichia coli \\
\hline 4 & 9.6 & 27 & 0.11 & 18700 & 72000 & 36.40 & HMC: Streptococcus pyogenes \\
\hline 5 & 13.6 & 39 & 0.02 & 16400 & 16000 & 9.30 & HMC: Enterobacter cloacae \\
\hline 6 & 13.6 & 38 & 0.20 & 21000 & 193000 & - & HMC: Streptococcus pyogenes \\
\hline 7 & 14.7 & 42 & 0.01 & 14900 & 560000 & - & HMC: Staphylococcus aureus \\
\hline 8 & 18.3 & 52 & 0.10 & 6500 & 111000 & 14.20 & HMC: Enterobacter aglomerans \\
\hline 9 & 7.8 & 21.1 & 0.22 & 4900 & 72000 & 203.00 & HMC: Staphylococcus aureus \\
\hline 10 & 12.0 & 34 & 0.21 & 10100 & 206000 & 3.30 & HMC: Enterobacter aglomerans \\
\hline 11 & 8.5 & 24 & 0.02 & 10300 & 610000 & - & HMC: Enterobacter cloacae \\
\hline 12 & 9.2 & 26 & 0.20 & 11000 & 72000 & 132.20 & HMC: Staphylococcus aureus \\
\hline 13 & 10.6 & 32 & 0.21 & 20600 & 144000 & 57.50 & Pus articulation Staphylococcus aureus \\
\hline 14 & 7.9 & 24 & 0.04 & 3700 & 200000 & 37.30 & LCR: Neisseria meningitidis \\
\hline 15 & 12.5 & 36 & 0.20 & 11800 & 272000 & 21.00 & HMC: Corynebacterium sp \\
\hline 16 & 10.0 & 28 & 0.30 & 4800 & 80000 & - & HMC: Enterococcus faecalis \\
\hline 17 & 11.5 & 31 & 0.30 & 3900 & 186000 & - & Ascitic liquid: Pseudomonas aeruginosa \\
\hline 18 & 11.1 & 32 & 0.20 & 21700 & 350000 & - & HMC: Staphylococcus aureus \\
\hline 19 & 9.4 & 27 & 0.20 & 24900 & 429000 & - & HMC: Enterococcus faecalis \\
\hline
\end{tabular}

CRP: C-reactive protein; Hb: Hemoglobin; Hct: Hematocrit; NI: Neutrophil Index. 
Table 2 Complete blood count, CRP and cultures on recovery phase of sepsis

\begin{tabular}{|c|c|c|c|c|c|c|c|}
\hline Case & $\mathrm{Hb}(\mathrm{g} / \mathrm{dl})$ & Hct (\%) & Leukocyte $/ \mathrm{mm}^{3}$ & $\mathrm{NI}$ & Platelet $/ \mathrm{mm}^{3}$ & CRP (mg/l) & Cultures \\
\hline 1 & 14.6 & 42 & 7900 & 0.06 & 200000 & 2.98 & Negative \\
\hline 2 & 11.2 & 32 & 10700 & 0.04 & 75000 & 2.00 & Negative \\
\hline 3 & 12.0 & 35 & 10000 & 0.05 & 130000 & - & - \\
\hline 4 & 9.3 & 28 & 11700 & 0.06 & 400000 & 3.30 & Negative \\
\hline 5 & 13.3 & 36 & 11400 & 0.09 & 120000 & - & Negative \\
\hline 6 & 12.0 & 34 & 12000 & 0.08 & 146000 & - & - \\
\hline 7 & 13.1 & 40 & 9600 & 0.05 & 210000 & - & Negative \\
\hline 8 & 11.5 & 35 & 11800 & 0.01 & 210000 & 7.00 & Negative \\
\hline 9 & 11.7 & 35 & 12800 & 0.05 & 390000 & 9.00 & Negative \\
\hline 10 & 9.9 & 28 & 8500 & 0.10 & 250000 & 3.40 & Negative \\
\hline 11 & 12.5 & 36 & 9700 & 0.07 & 395000 & 6.00 & Negative \\
\hline 12 & 10.4 & 30 & 8100 & 0.05 & 570000 & 3.40 & Negative \\
\hline 13 & 9.1 & 27 & 7400 & 0.04 & 319000 & 8.00 & Negative \\
\hline 14 & 10.6 & 31 & 13600 & 0.10 & 190000 & - & Negative \\
\hline 15 & 12.2 & 36 & 12100 & 0.10 & 177000 & - & Negative \\
\hline 16 & 14.6 & 42 & 7900 & 0.06 & 200000 & 2.98 & Negative \\
\hline 17 & 11.2 & 32 & 10700 & 0.04 & 75000 & 2.00 & Negative \\
\hline 18 & 12.0 & 35 & 10000 & 0.05 & 130000 & - & - \\
\hline 19 & 9.3 & 28 & 11700 & 0.06 & 400000 & 3.30 & Negative \\
\hline
\end{tabular}

CRP: C-reactive protein; Hb: Hemoglobin; Hct: Hematocrit; NI: Neutrophil Index.

that at the recovery phase REE was increased compared to the acute sepsis phase, probably due to the resumption of growth. Albeit we investigated a small number of newborns, statistical analysis showed significant differences between acute and recovery phases of sepsis.

In adults with bacterial sepsis it has been shown that caloric and protein needs increased by as much as $150 \%$ of normal basal metabolism rate [22]. In this age group equations for calculating caloric requirements are often used; one of the best known is the Harris-Benedict. However, this equation tends to overestimate the caloric needs [23].

We reported that $\mathrm{VO}_{2}$ and $\mathrm{VCO}_{2}$ were increased at the recovery phase of sepsis. There are few studies

Table 3 Clinical profile of each newborn during acute phase of sepsis

\begin{tabular}{|c|c|c|c|c|c|c|}
\hline Case & Infection & $\begin{array}{l}\text { Hypothermy } \\
\left(T<36^{\circ} \mathrm{C}\right)\end{array}$ & $\begin{array}{l}\text { Hyperthermy } \\
\left(T>37,5^{\circ} \mathrm{C}\right)\end{array}$ & $\begin{array}{l}\text { Tachycardia } \\
\text { (>120 bpm) }\end{array}$ & Tachypnea (>40/min) & Antibiotics \\
\hline 1 & YES & YES & $\mathrm{NO}$ & YES & YES & Vancomycin and Cefotaxime \\
\hline 2 & YES & NO & NO & YES & YES & Ceftazidime and Imipenem \\
\hline 3 & YES & NO & YES & YES & NO & Ceftriaxone \\
\hline 4 & YES & YES & NO & YES & YES & Penicillin and Amicacine \\
\hline 5 & YES & NO & YES & YES & YES & Vancomycin and Cefotaxime \\
\hline 6 & YES & YES & NO & YES & YES & Ampicillin and Amicacine \\
\hline 7 & YES & NO & YES & YES & YES & Oxacillin \\
\hline 8 & YES & YES & NO & NO & YES & Vancomycin and Cefotaxime \\
\hline 9 & YES & NO & YES & YES & YES & Vancomycin and Ceftriaxone \\
\hline 10 & YES & NO & NO & YES & YES & Penicilyin and Amicacine \\
\hline 11 & YES & NO & NO & YES & YES & Vancomycin and Cefotaxime \\
\hline 12 & YES & NO & YES & YES & YES & Vancomycin and Ceftriaxona \\
\hline 13 & YES & NO & NO & YES & YES & Vancomycin and Ceftriaxona \\
\hline 14 & YES & NO & YES & YES & YES & Penicillin and Amicacine \\
\hline 15 & YES & NO & YES & YES & YES & Vancomycin and Cefotaxime \\
\hline 16 & YES & YES & NO & YES & YES & Oxacillin and Amicacine \\
\hline 17 & YES & YES & NO & YES & YES & Vancomycin and Imipenem \\
\hline 18 & YES & YES & NO & YES & YES & Vancomycin and Cefoxitin \\
\hline 19 & YES & NO & YES & YES & YES & Meropenen \\
\hline
\end{tabular}




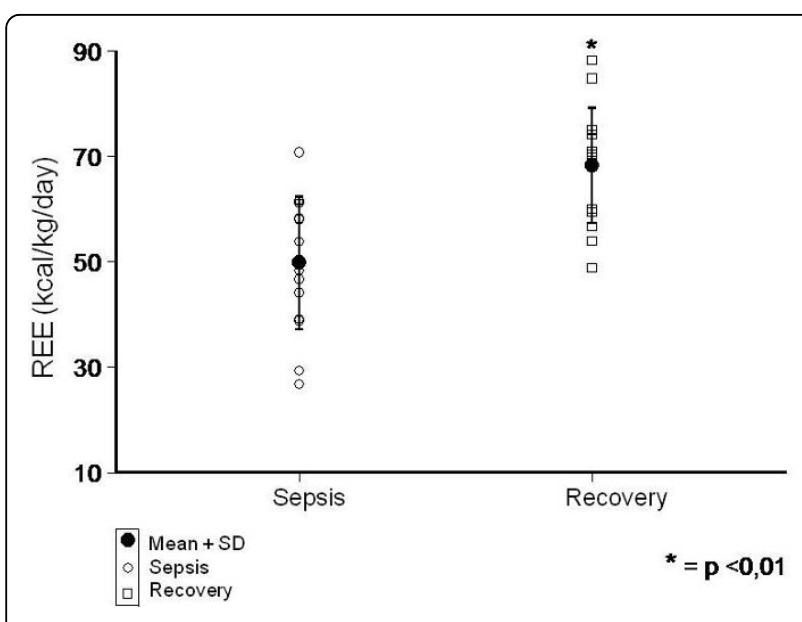

Figure 1 Comparison of REE ( $\mathrm{kcal} / \mathrm{kg} /$ day) between sepsis and recovery phase.

where the energy requirements in children and especially in newborns with bacterial sepsis were evaluated and the clinically utilized data in neonates was extrapolated from adult values [24]. The application of various predictive equations of REE for children under mechanical ventilation as the Harris-Benedict and Talbot equations formulas overestimate the caloric requirement $[25,26]$.

Nevertheless, other studies have reported decreased basal metabolic rate in sick children. Powis et al [27] evaluated children undergoing major surgery and did not report an increase in basal metabolic rate during the postoperative period of six newborns with necrotizing enterocolitis. Chwals [28] evaluated the overfeeding (over nutrition) associated to the metabolic effects which occur when nutritionally supporting extremely ill children. The author concluded that the caloric

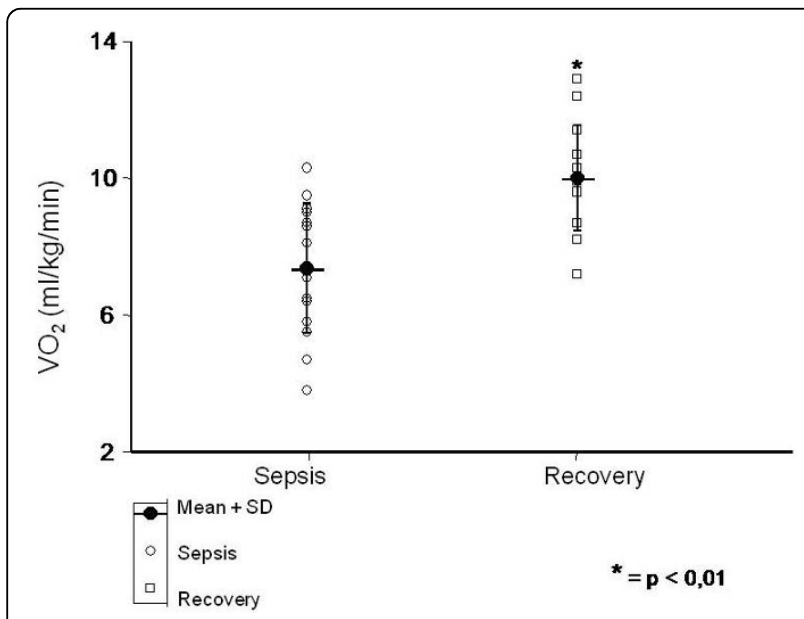

Figure 2 Comparison of $\mathrm{VO}_{2}(\mathrm{ml} / \mathrm{kg} / \mathrm{min})$ between sepsis and recovery phase.

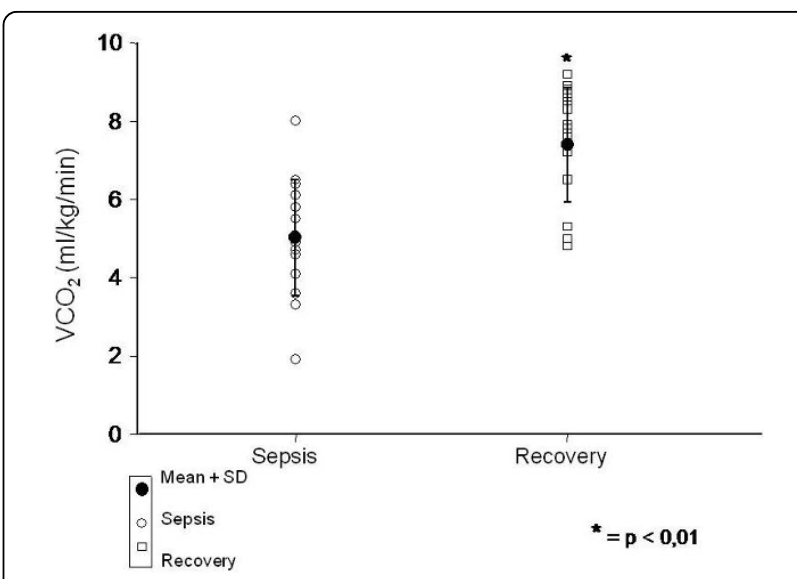

Figure 3 Comparison of $\mathrm{VCO}_{2}(\mathrm{ml} / \mathrm{kg} / \mathrm{min})$ between sepsis and recovery phase.

requirement of these children are unpredictable and modified by disease, age, previous nutritional status and type of nutrients (especially parenteral use) with varied specific dynamic action. Therefore, the caloric requirements of critically ill children should be assessed individually and measured by appropriate techniques.

In our study we measured REE through indirect calorimetry. Several techniques are used to evaluate the basal metabolism rate or REE. The most used is the indirect calorimetry, due to its accuracy, portability, comfort and safety for the patient, even in seriously ill subjects [29]. The equipment and technique utilized in the present study were developed by Hamamoto [19] and are especially appropriate for newborns and young children. The method validation was performed by measuring REE in newborns and comparing the results with data from studies that used the same technique. During our study there were no changes in the oxygen saturation and axillary temperature of the newborns. The technique is utilized in our center as part of the patient assessment and it is used frequently for children with metabolic disorders and/or to determine adequacy of nutritional support [19].

We found that REE averaged $49.4 \pm 13.1$. These values are very close to those of a previous study $(51.7 \pm 6.21$ $\mathrm{kcal} / \mathrm{kg} /$ day), which used the same apparatus and technique. In the present study, the highest REE during sepsis was $70.7 \mathrm{kcal} / \mathrm{kg} /$ day. Considering that in normal children the average REE is $58 \mathrm{kcal} / \mathrm{kg} /$ day [25], only six study subjects showed REE values above the normal range. Even in one case the REE was $70.7 \mathrm{kcal} / \mathrm{kg} / \mathrm{day}$, which represents only $20 \%$ above the highest reference value.

We reported that some of the newborns died during our study. The analysis of REE data in these subjects showed that two neonates exhibited REE values (51.7 \pm 
Table 4 Age (days) and weight ( $g$ ) at sepsis and recovery phase of sepsis

\begin{tabular}{|c|c|c|c|c|c|c|c|}
\hline \multirow[t]{2}{*}{ Case } & \multicolumn{3}{|c|}{ Age (days) } & \multicolumn{4}{|c|}{ Weight (g) } \\
\hline & Hospitalization & Sepsis & Recovery & Birth & Hospitalization & Sepsis & Recovery \\
\hline 1 & 24 & 31 & 41 & 3030 & 3295 & 3570 & 3620 \\
\hline 2 & 6 & 28 & 39 & 3070 & 2820 & 2535 & 2750 \\
\hline 3 & 13 & 14 & 25 & 3230 & 3580 & 3480 & 3630 \\
\hline 4 & 18 & 30 & 50 & 2630 & 2730 & 2685 & 3520 \\
\hline 5 & 1 & 10 & 24 & 1800 & 1680 & 1695 & 2000 \\
\hline 6 & 1 & 2 & 13 & 2750 & 2760 & 2580 & 2600 \\
\hline 7 & 22 & 25 & 35 & 2730 & 3640 & 3565 & 3750 \\
\hline 8 & 9 & 11 & 26 & 3500 & 3000 & 3080 & 3040 \\
\hline 9 & 16 & 20 & 42 & 3000 & 3130 & 2780 & 2890 \\
\hline 10 & 31 & 33 & 44 & 3640 & 3580 & 3570 & 3980 \\
\hline 11 & 51 & 57 & 69 & 3300 & 4500 & 4710 & 4965 \\
\hline 12 & 15 & 21 & 44 & 3440 & 3660 & 4130 & 3180 \\
\hline 13 & 27 & 33 & 54 & 2580 & 2760 & 2490 & 2990 \\
\hline 14 & 63 & 69 & 81 & 1960 & 4015 & 3880 & 4365 \\
\hline 15 & 4 & 7 & 28 & 3530 & 3300 & 3700 & 3570 \\
\hline 16 & 30 & 34 & - & 3200 & 3900 & 3885 & - \\
\hline 17 & 6 & 11 & - & 2930 & 2725 & 3070 & - \\
\hline 18 & 1 & 45 & - & 3470 & 3470 & 2690 & - \\
\hline 19 & 35 & 38 & - & 3150 & 2430 & 2510 & - \\
\hline Mean & 19.6 & 27.3 & 41 & 2996.8 & 3209.2 & 3189.7 & 3390 \\
\hline Median & 16 & 28 & 41 & 3070 & 3295 & 3080 & 3520 \\
\hline SD & 17.1 & 17.2 & 17.8 & 502.3 & 647.9 & 730.9 & 737.3 \\
\hline Maximum & 63 & 69 & 81 & 3640 & 4500 & 4710 & 4965 \\
\hline Minimum & 1 & 2 & 13 & 1800 & 1680 & 1695 & 2000 \\
\hline
\end{tabular}

$6.21 \mathrm{kcal} / \mathrm{kg} /$ day) within the adopted reference range. However, we observed that newborns showing significantly lower REE values were more likely to have a poor outcome. In fact, the infant who presented one of the lowest REE (27.8 kcal/kg/day) quickly evolved to demise. Briassoulis et al [25] proposed that the measurement of basal metabolism rate may be a prognostic factor for mortality: the lower the value, the greater the odds of a poor prognosis.

Based on our results, we found no hypermetabolism, differently from what is established in adults with bacterial sepsis where REE is estimated at $100-150 \%$ higher than the values of basal metabolism. The same can be said about the $\mathrm{VO}_{2}$ and $\mathrm{VCO}_{2}$. The average $\mathrm{VO}_{2}$ of our study was $7.4 \pm 1.9 \mathrm{ml} / \mathrm{kg} / \mathrm{min}$, similar to the value of $7.41 \pm 0.88 \mathrm{ml} / \mathrm{kg} / \mathrm{min}$ verified by Hamamoto [19]. The $\mathrm{VCO}_{2}$ during acute phase of sepsis averaged $5.1 \pm 1.7$ $\mathrm{ml} / \mathrm{kg} / \mathrm{min}$, which was below the average of $6.36 \pm 1.04$ reported by the authors. The lower values likely relate to changes in energy metabolism and burning fat and preferential ketone bodies, which frequently occurs in malnourished children and low-calorie-protein intake. This assumption is also supported by the analysis of the $R Q$. The $R Q=0.7$ we found during sepsis is indicative of the predominant combustion of fat and ketone bodies, resulting in lower $\mathrm{CO}_{2}$ production.

The proposed explanation for our results regarding REE, i.e. the absence of hypermetabolism energy has not been adequately discussed in the literature. Nonetheless, some studies related to bacterial sepsis in children are relevant to our analysis. Uzel and Neyzi [30] studied thyroid function in severely infected children and they reported that the values of thyroxine $\left(\mathrm{T}_{4}\right)$ and thyroidstimulating hormone (TSH) were comparable to normal controls, whereas triiodothyronine $\left(\mathrm{T}_{3}\right)$ were much lower and triiodothyronine (reverse $\mathrm{rT}_{3}$ ) were higher. Mendoza-Morfin et al [31] investigated infants with bacterial sepsis and observed reduction of $\mathrm{T}_{4}$ and $\mathrm{T}_{3}$ associated to increase of $\mathrm{rT}_{3}$ and $\mathrm{TSH}$. After the recovery of sepsis these values returned to normal in children who survived. The authors suggested that through these hormonal changes positively contributed to prevent sepsisinduced catabolism. Furthermore, Hatherill et al [32] evaluated adrenal function in infants with septic shock and demonstrated adrenal insufficiency in 52\% of cases. The consequence of this fact was reflected in higher mortality, severe hypotension and more frequent use of vasoactive drugs to maintain blood pressure. Togari 
et al [33], on the same line of research, demonstrated a decrease of plasma cortisol in children with endotoxic shock. The analysis of these studies showed a reduction of $\mathrm{T}_{3}$, cortisol and catecholamines mainly caused by adrenal insufficiency, an important fact because the triiodothyronine and catecholamines are hormones that promote the body thermogenesis. Probably the interpretation of our results with respect to the absence of hypermetabolism energy in children during the acute phase of sepsis is explained by hormonal changes described above.

The present study has the following caveats. Firstly, we decided not to use a control group since energy expenditure in healthy newborns is well described in the literature [34] and in this investigation we opted to comparatively evaluate the changes in the same infant over time (acute sepsis phase and recovery phase). Secondly, parenteral [28], enteral and oral feeding influence REE [35] and we evaluated newborns which received parenteral feeding. Thirdly, we did not perform any multivariate analysis in order to assess the study variables although this could have provided more detailed information regarding REE. We suggest further studies to evaluate this issue. Fourthly, newborns did not require higher $\mathrm{FIO}_{2}$ and were not mechanically ventilated. These results are not supported by Kreymann et al [36], who found a normal or only slightly elevated REE in adult patients with severe sepsis or septic shock but a hypermetabolic response in patients with uncomplicated sepsis. It is possible that this apparent conflict can be explained by standardization approach described in our method section.

In summary, during the acute phase of bacterial sepsis REE was significantly reduced, as compared with the subsequent recovery phase of sepsis. We recommend that REE during the acute phase of sepsis be individualized for each child, taking into account the severity of the disease, the degree of malnutrition and the type of energy substrate used with respect to the metabolic capacity of the child.

\section{Acknowledgements}

We thank Dr. Jaques Belik for critical review English Grammar and neonatal concepts. We thank the Medical School of University of São Paulo for financial support.

\section{Author details}

'Departamento de Pediatria, Universidade de São Paulo (USP), São Paulo, SP, Brasil. 'Departamento de Saúde Materno-infantil, Universidade de São Paulo (USP), São Paulo, SP, Brasil. ${ }^{3}$ Departamento de Medicina, Disciplina de Cardiologia, Universidade Federal de São Paulo (UNIFESP), São Paulo, SP, Brasil. ${ }^{4}$ Departamento de Morfologia e Fisiologia, Faculdade de Medicina do ABC, Santo André, SP, Brasil.
}

\section{Authors' contributions}

RF, VEV, LCA, CL, AAFS, AGO and TDC designed research, analyzed data, and wrote the paper. RF, VEV, PRG, AOAR, RW and LCA carried out the statistical analysis and participated in design the manuscript. All authors read and approved the final manuscript.

\section{Competing interests}

The authors declare that they have no competing interests.

Received: 9 March 2010 Accepted: 23 July 2010 Published: 23 July 2010

References

1. Shmerling DH: Development of digestive and absorptive function in the human fetus. Nutr Metab 1976, 20:76-9.

2. Ceccon MEJR, Krebs VLJ, Vaz FAC: Sepsis in neonatal period. Pediatr Mod 2000, 36:174-9.

3. Hommes FA: The energy requirement for growth. A reevaluation. Nutr Metab 1980, 24:110-3.

4. Oshikoya KA, Senbanjo IO: Pathophysiological changes that affect drug disposition in protein-energy malnourished children. Nutr Metab 2009, 6:50.

5. Bauer J, Werner C, Gerss J: Metabolic rate analysis of healthy preterm and full-term infants during the first weeks of life. Am J Clin Nutr 2009, 90:1517-24.

6. Bauer J, Teufel U, Maser-Gluth C, Doege C: Effects of budesonide inhalation on energy expenditure, somatic growth and salivary cortisol levels in preterm infants with chronic lung disease. Horm Res 2009, 72:146-52

7. McHoney M, Eaton S, Pierro A: Metabolic response to surgery in infants and children. Eur J Pediatr Surg 2009, 19:275-85.

8. Pierro A, Eaton S: Metabolism and nutrition in the surgical neonate. Semin Pediatr Surg 2008, 17:276-84.

9. Cañete A, Duggan C: Nutritional support of the pediatric intensive care unit patient. Curr Opin Pediatr 1996, 8:248-55.

10. Jüttner B, Kröplin J, Coldewey SM, Witt L, Osthaus WA, Weilbach C, Scheinichen : Unsaturated long-chain fatty acids induce the respiratory burst of human neutrophils and monocytes in whole blood. Nutr Metab 2008, 5:19.

11. Bone RC: The pathogenesis of sepse. Ann Intern Med 1991, 115:457-69.

12. Jaye $\mathrm{DL}$, Waites KB: Clinical applications of C-reactive protein in pediatrics. Pediatr Infect Dis J 1997, 16:735-47.

13. Fehling $C$, Jägerstad M: Vitamin B12 deprivation in the rat: effects on folate metabolism with emphasis on the nervous system. Nutr Metab 1978, 22:90-100.

14. Feferbaum R: Parenteral nutrition in newborn with prolonged diarrhea. São Paulo; MSc - Faculdade de Medicina da Universidade de São Paulo 1983.

15. Capurro H, Konichezky S, Fonseca D, Caldeyro-Barcia R: A: Simplified method for diagnostic of gestacional age in the newborn infant. $J$ Pediatr 1978, 93:102-12.

16. Ramos $\mathrm{LA}$ : Evaluation of intra-uterin growth by anthropometric measurement in newborns. São Paulo; PhD - Faculdade de Medicina da Universidade de São Paulo 1983.

17. Cardoso AL, Carraza FR, Mariano MA, Gomes C, Saraiva PAP: Energy balance during malnourished newborns with diarrhea hospitalization. Rev Paul Pediatr 1991, 9:142-6.

18. Bauer K, Pasel K, Uhrig C, Sperling P, Versdmold H: Comparison of face mask, head hood, and canopy for breath sampling of flow through indirect calorimetry to measure oxygen consumption and carbon monoxide production of preterm infants less than 1500 grams. Pediatr Res 1997, 41:139-144.

19. Hamamoto LA, Cardoso AL, Marques HH, Gomes C: Energy balance in infants born from HIV seropositive mothers. J Pediatr 2000, 76:119-24.

20. Scopes JW, Ahmed I: Range of critical temperatures in sick and newborn babies. Arch Dis Child 1966, 41:417.

21. Li J, Zhang G, Herridge J, Holtby H, Humpl T, Redington AN, Van Arsdell GS: Energy expenditure and caloric and protein intake in infants following the Norwood procedure. Pediatr Crit Care Med 2008, 9:55-61.

22. Long CL, Schaffel N, Geiger JW: Metabolic response to injury and illness: estimation of energy and protein needs from indirect calorimetry and nitrogen balance. J Parent Enteral Nutr 1979, 3:452.

23. O'Riordan CF, Metcalf BS, Perkins JM, Wilkin TJ: Reliability of energy expenditure prediction equations in the weight management clinic. $J$ Hum Nutr Diet 2010, 23:169-75. 
24. Wahlig TM, Georgieff MK: The effects of illness on neonatal metabolism and nutritional management. Clin Perinatol 1995, 33:77-96.

25. Briassoulis G, Venkataraman S, Thompson AE: Energy expenditure in critically ill children. Crit Care Med 2000, 28:166-72.

26. Coss-Bu JA, Jefferson LS, Walding D, David Y, Smith EO, Klish WJ: Resting energy expenditure and nitrogen balance in critically ill pediatric patients on mechanical ventilation. Nutrition 1988, 14:649-52.

27. Powis MR, Smith K, Rennie M, Halliday D, Pierro A: Effect of major abdominal operations on energy and protein metabolism in infants and children. J Pediatr Surg 1998, 33:49-53.

28. Chwals WJ, Lally KP, Woolley MM: Measured energy expenditure in critically ill infants and young children. J Surg Res 1988, 44:467-72.

29. Pencharz PB: A new approach to measure energy expenditure in the neonate. Pediatr Res 2000, 47:707-8.

30. Uzel N, Neyzi O: Thyroid function in critically ill infants with infections. Pediatr Infect Dis J 1986, 5:516-9.

31. Mendoza-Morfín F, Vaca-Arellano MR, Toledo-Villalpando AD, OlveraHidalgo C, Mondragón-Rosales L, Junco-Lorenzana E: The quantitative analysis of thyroid hormones and thyrotropin in children critically ill with septicemia. Bol Med Hosp Infant Mex 1991, 48:230-4.

32. Hatherill M, Tibby SM, Hilliard T, Turner C, Murdoch IA: Adrenal insufficiency in septic shock. Arch Dis Child 1999, 80:51-5.

33. Togari H, Sugiyama S, Ogino T, Suzuki S, Ito T, Ichiki T, Kamiya K, Watanabe I, Ogawa Y, Wada Y: Interactions of endotoxin with cortisol and acute phase proteins in septic shock. Acta Paediatr Scand 1986, 75:69-74

34. Fusch C, Bauer K, Böhles HJ, Jochum F, Koletzko B, Krawinkel M, Krohn K, Mühlebach $\mathrm{S}$, Working group for developing the guidelines for parenteral nutrition of The German Society for Nutritional Medicine: Neonatology/ Paediatrics - Guidelines on Parenteral Nutrition, Chapter 13. Ger Med SCi 2009, 7, NDoc15.

35. Ista $\mathrm{E}$, Joosten $\mathrm{K}$ : utritional assessment and enteral support of critically ill children. Crit Care Nurs Clin North Am 2005, 17:N385-93.

36. Kreymann G, Grosser S, Buggisch P, Gottschall C, Matthaei S, Greten H: Oxygen consumption and resting metabolic rate in sepsis, sepsis syndrome, and septic shock. Crit Care Med 1993, 21:1012-9.

doi:10.1186/1743-7075-7-63

Cite this article as: Feferbaum et al:: Rest energy expenditure is decreased during the acute as compared to the recovery phase of sepsis in newborns. Nutrition \& Metabolism 2010 7:63.

\section{Submit your next manuscript to BioMed Central and take full advantage of:}

- Convenient online submission

- Thorough peer review

- No space constraints or color figure charges

- Immediate publication on acceptance

- Inclusion in PubMed, CAS, Scopus and Google Scholar

- Research which is freely available for redistribution

Submit your manuscript at www.biomedcentral.com/submit
Biomed Central 